\title{
Assessment of Barriers to Exclusive Breast Feeding Among Working Saudi Mothers
}

\author{
Nisreen Kh. Aref Albezrah ${ }^{1}$, Haneen Ali Alshehri ${ }^{* 2}$, Raghad Hilal Alswat ${ }^{2}$, Manal Saeed Almalki ${ }^{2}$, \\ Atheer Mohammed Al fuhayd ${ }^{2}$, Reem Abdullah Alkenany ${ }^{2}$, Shrooq Homood Alswat ${ }^{2}$, Khames T. Alzahrani ${ }^{3}$ \\ ${ }^{1}$ Professor Obstetric and Gynecology, Obstetric and Gynecology Department, Medical College, Taif University, \\ Taif, Saudi Arabia \\ ${ }^{2}$ Medical Student, Taif University, Taif, Saudi Arabia \\ ${ }^{3}$ BDS, PGD Endo, Ministry of Health, Saudi Arabia
}

*Corresponding author: Haneen Ali Alshehri; dr.alhehrhaneen @ gmail.com

Received 07 September 2021;

Accepted 23 September 2021;

Published 02 October 2021

\begin{abstract}
Background: The World Health Organization and the United Nations International Children's Fund recommend mothers to exclusively breastfeed their infants for the first six months of their life that should be initiated within the first hour after birth. Methods: This cross-sectional study included currently employed Saudi working mothers residing the Western region of Saudi Arabia. A self-administered questionnaire was distributed through email and social media. Each person meeting the inclusion criteria was provided informed consent, explaining the study aim, and ensuring the confidentiality of information. Data were obtained by filling out the designed Questionnaire. Result: This study included 692 working Saudi mothers. The frequency of exclusive breast feeding was $40.2 \%$, which was continued by $29.8 \%$ only after returning to the work. Insufficient breast milk secretion (17.5\%) and the lack or minimal support from the workplace for EBF (6.6\%) were commonly stated by the mothers. There were great deficiencies in the breastfeeding friendly work policies including the absence of breast feeding or breast milkpumping place $(86.4 \%)$, absence of breastfeeding hours during work time $(80.9 \%)$, and the presence of a strict full-time schedule that did not allow freely use of the nursing break. Conclusion: The present study shows low prevalence of exclusive breast feeding among working mothers in the Western region of Saudi Arabia. Multiple barriers to continuing breast feeding have been detected. Insufficient breast milk secretion and the lack of breastfeeding friendly work policies were common reasons.
\end{abstract}

Keywords: Exclusive Breast Feeding, Working Mothers, Barriers, Saudi Arabia, Friendly Work Policies.

\section{Introduction}

The World Health Organization (WHO) and the United Nations International Children's Fund recommend mothers to exclusively breastfeed their infants for the first six months of their life that should be initiated within the first hour after birth ${ }^{[1]}$. The WHO defines exclusive breast feeding $(\mathrm{EBF})$ as the practice of feeding an infant only on mother's milk for the first six months of life without the addition of any other substance ${ }^{[2]}$. Evidence shows that EBF is beneficial to both the child and the mother, as it improves the cognitive development of the child, strengthens the immune system, and lowers the risks of many acute and chronic conditions, such as infections, obesity, cancers, asthma, allergies, cardiovascular and metabolic diseases, and sudden infant death syndrome ${ }^{[3,4]}$. Some of the benefits that mothers achieve are minimal postpartum bleeding, decreased menstrual blood loss, faster return to pre-pregnancy weight, and lower incidence of breast and ovarian cancer. Along with these health benefits, the working mother also attains some economic benefits such as higher employee productivity and lower absenteeism, increased employment retention by working mothers who breastfeed, cost savings by avoiding the purchase of infant formula, and decreased health care costs resulting in savings to public and private insurers $^{[5,6]}$.

A study conducted in Australia by Cooklin et al. (2008) reported that working women had difficulty in breastfeeding their infants in the first 6 months of life due to decreased support from the workplace that contributed to premature cessation of breastfeeding ${ }^{[7]}$. Another study done in the United States by Carlson-Gielen et al. (1991) had found that Mothers were much less likely to terminate breastfeeding at 12 weeks postpartum if they reported (during the 12-week interview) having earned encouragement from their clinician to breastfeed. It also has been reported the women on full-time employment in the first postpartum year has a strong negative effect on breastfeeding duration ${ }^{[8]}$. 
The Eastern Mediterranean Regional Office of WHO has reported high rates $(>60 \%)$ of early breastfeeding initiation but there was a decline in $\mathrm{EBF}(<40 \%)$ for the infant under 6 months in the Middle East and North Africa countries ${ }^{[9]}$. According to the World Bank data, the current female labor force in the Kingdom of Saudi Arabia in 2020 is $15.9 \%$ of the total workforce, and the vision 2030 aims to increase the female participation in the workforce from the current rate to $40 \%{ }^{[10]}$. This means that female workforce in the labor market is increasing in Saudi Arabia and working mothers' need a safe environment to breast feed their infants at the workplace. A Study done in the Tabuk region of Saudi Arabia had reported an EBF rate of $31.4 \%$ that identified working Saudi women who practiced this attitude compared to non-working women ${ }^{[11]}$. Another study done in Primary Health Care women workers in the Al-Ahsa region of Saudi Arabia showed that $43.5 \%$ of them exclusively breastfeed their infants beyond six months. There is a lack of data regarding EBF in women working in different sectors in the Kingdom especially in the Western region ${ }^{[12]}$. Hence, this study aimed to assess the rate of EBF and identify the associated factors that influence this practice among Saudi working mothers in the western region of Saudi Arabia (Jeddah, Makkah, Taif, etc)

The objectives of our study were to (a) estimate the rate of EBF in working Saudi mothers irrespective of the job sector in the Western region of Saudi Arabia (Jeddah, Makkah, Taif, etc.) (b) determine the barriers faced by those mothers regarding EBF in the first six months of the child's life, and (c) assess the relationship of these barriers and factors to the rate of EBF.

\section{Methods}

\section{Study design}

A cross-sectional study was conducted among employed Saudi females who are married and has an infant(s) at breastfeeding age in the Westren region of Saudi Arabia (Jeddah,Mecca and Taif). A pretested and validated questionnaire was used to collect data on sociodemographic characteristics, work-related characteristics, rate of EBF, and barriers related to EBF. The study obtained approval from the Research and Ethics Committee of College of Medicine, Taif University, Saudi Arabia.

\section{Sampling and sample size calculation}

A pilot was done to calculate the minimum sample size for our study by considering the values derived from the pilot study that was conducted among 50 females of the same characteristics. A minimum sample size 613 was calculated at $95 \%$ confidence interval and $80 \%$ power of study. A mixture of convenience and snowball sampling were used to collect the required samples. The questionnaire was sent to the general population via email, social media (WhatsApp, Facebook, Instagram, etc.). The responses were checked regarding eligibility criteria for further analysis.

\section{Inclusion criteria}

Currently employed mothers working in any sector residing in Western region of Saudi Arabia (Jeddah, Makkah, Taif, etc.), age between 18 and 50 years and Saudi nationality.

\section{Exclusion criteria}

Mothers who delivered a child before being employed ,mothers below 18 years old, or older than 50,any married female who has not had children,Single females, Non-Saudi workers and those who didn't give consent to participate.

\section{Questionnaire}

The items used in our questionnaire were adopted from similar studies done by Al-Katufi et al. (2020) and Alsulaimani (2019). The questionnaire showed an internal consistency, Cronbach's alpha of 0.83 . The questionnaire consisted of three parts, A, B, and C. A statement of confidentiality and anonymity was given at the beginning of the questionnaire and informed consent was taken from the participants ${ }^{[12,13]}$.

The part A of the questionnaire recorded sociodemographic details including age, highest educational level, marital status, number of children, and medical history of the mother and the child. Part B included knowledge, fear, and perceptions regarding breastfeeding, details on prenatal and postpartum support from the workplace and family members, illness or fatigue, medication use, and maternal stress. Part C reported the work-related characteristics including employment status, work shift, hours worked per day, breastfeeding support services, availability of breastfeeding or breast pumping being offered to breastfeed or to breast pump during breaks in work hours, the presence of a feeding room, and the presence of a policy supporting employees to breastfeed or express milk in their workplace.

\section{Statistical analysis}

The data were represented and analyzed using SPSS Ver 22 (IBM Corp. USA). Categorical data were represented as frequencies and percentages. Apparent associations between categorical variables were analyzed using Pearson's Chi-square and Fisher's Exact tests as appropriate. Continuous data were tested for normality by the Shapiro Wilk test, and normally distributed data were presented as mean \pm standard deviation, while non-normally distributed data were presented as median and interquartile rang. A $p$ value $<0.05$ was considered statistically significant.

\section{Results}

This study included 692 working Saudi mothers residing the Western region of Saudi Arabia including Taif (57.8\%), Jeddah $(19.7 \%)$, and Makkah (16.7\%). Their mean age was $36 \pm 8.5$ years. More than half $(53.8 \%)$ were teachers, while workers in health care sector (physicians, dentists, pharmacists, nurses, and other jobs) represented 9.2\%. Administrative jobs and business work represented $16.2 \%$ and $7.9 \%$, respectively. The majority $(93.9 \%)$ were married, and divorced women constituted $6.1 \%$. Most of them (78.9\%) had University education. The majority reported full-time and morning shift working (67.1\% and $72.8 \%$, respectively). The median age of their infant was $8(\mathrm{IQR}=4-14)$ months (Table 1$)$.

The period between the last and the current pregnancy was three years or more in $50 \%$ of them. Few participants $(9.8 \%)$ reported postpartum problems such as back pain, teeth pain, lumber disc, diabetes, and fatigue and 103 (14.9\%) reported using drugs such as analgesics, vitamins, oral contraceptive pills besides medications for treatment of diabetes, hypertension, hypothyroidism. (Table 2).

Breast feeding behavior is demonstrated in Table 3 . Among the study participants, 557 (80.5\%) had previous breastfeeding experience, and about half of them (49.2\%) practiced breast feeding for more than 6 months. The frequency of exclusive breast feeding was $40.2 \%$, which was continued by $29.8 \%$ after returning to the work.

Table 4 illustrates barriers that prevent mothers from continuing exclusive breast feeding after returning to the work. Insufficient breast milk secretion $(17.5 \%)$ and the lack or minimal support from the workplace for EBF (6.6\%) were commonly stated 
by the mothers; however, the majority $(61.4 \%)$ identified a combination of more than one barrier.

There was a significant association between discontinuation of EBF after returning to the work and being a teacher $(57.8 \%$ versus $44.2 \%$ ) or working in administrative jobs ( $16.3 \%$ versus $16 \%)$. As well, significantly higher percent of mothers who discontinued EBF were working full-time $(\mathrm{p}=0.005)$, in the morning shift $(\mathrm{p}=0.001)$, developed postpartum medical conditions $(\mathrm{p}=0.011)$ or using drugs for the management of these medical conditions $(\mathrm{p}=0.047)$ (Table 5).

Workers in the health care sector who discontinued EBF after returning to their work reported significantly higher percent of insufficient breast milk secretion (19.1\% versus $0.0 \%)$ and the perception that formula feeding makes a good effect on babies' weight $(1.5 \%$ versus $0.0 \%)$ in comparison to those who continued EBF (Table 6).

Inquiring about breast feeding friendly work policy revealed high prevalence of absent breast feeding or breast milkpumping place $(86.4 \%)$, or breastfeeding hours during work time (80.9\%). Moreover, 592 (85.5\%) women reported that they did not breast feed their infants during the work time, and more than half $(53.0 \%)$ reported the presence of a strict full-time schedule that did not allow free use of the nursing break as illustrated in (Table 7).

Table 8 shows absent breastfeeding friendly work policies more significantly among women who discontinued EBF after returning to the work compared to their counterparts.

Table 1: Sociodemographic characteristics of the study participants

\begin{tabular}{|c|c|c|c|}
\hline & & $\mathbf{N}$ & $\%$ \\
\hline \multirow[t]{5}{*}{ City } & Taif & 399 & $57.8 \%$ \\
\hline & Jeddah & 136 & $19.7 \%$ \\
\hline & Makkah & 115 & $16.7 \%$ \\
\hline & others & 27 & $3.9 \%$ \\
\hline & Madinah & 13 & $1.9 \%$ \\
\hline \multirow[t]{9}{*}{ Occupation } & Teacher & 372 & $53.8 \%$ \\
\hline & Administrative jobs & 112 & $16.2 \%$ \\
\hline & Others & 88 & $12.7 \%$ \\
\hline & Business & 55 & $7.9 \%$ \\
\hline & Physician/dentist & 23 & $3.3 \%$ \\
\hline & Other job in health care sector & 20 & $2.9 \%$ \\
\hline & Nurse & 11 & $1.6 \%$ \\
\hline & Pharmacist & 10 & $1.4 \%$ \\
\hline & Engineer & 1 & $0.1 \%$ \\
\hline \multirow[t]{2}{*}{ Marital status } & Married & 649 & $93.9 \%$ \\
\hline & Divorced & 42 & $6.1 \%$ \\
\hline \multirow[t]{3}{*}{ Highest educational level } & University & 545 & $78.9 \%$ \\
\hline & Pre-university & 84 & $12.1 \%$ \\
\hline & Postgraduate & 62 & $9.0 \%$ \\
\hline \multirow[t]{2}{*}{ Employment status } & Full-time & 464 & $67.1 \%$ \\
\hline & Part-time & 228 & $32.9 \%$ \\
\hline \multirow[t]{4}{*}{ Work shift } & Morning & 504 & $72.8 \%$ \\
\hline & Multishift & 123 & $17.8 \%$ \\
\hline & Evening & 58 & $8.4 \%$ \\
\hline & Night & 7 & $1.0 \%$ \\
\hline \multirow[t]{3}{*}{ Infant gender } & Female & 339 & $49.0 \%$ \\
\hline & Male & 324 & $46.8 \%$ \\
\hline & Twins & 29 & $4.2 \%$ \\
\hline \multirow[t]{4}{*}{ How many children do you have? } & 1 & 161 & $23.3 \%$ \\
\hline & 2 & 138 & $19.9 \%$ \\
\hline & $3-4$ & 241 & $34.8 \%$ \\
\hline & 5 or more & 152 & $22.0 \%$ \\
\hline
\end{tabular}

Table 2: Medical and postpartum history of the study participants

\begin{tabular}{|l|l|l|l|}
\hline \multirow{2}{*}{ Parity } & $\mathbf{N}$ & $\mathbf{N}$ & $\mathbf{\%}$ \\
\cline { 2 - 4 } & 2 & 634 & $91.6 \%$ \\
\cline { 2 - 4 } & 2 & 37 & $5.3 \%$ \\
\hline \multirow{3}{*}{ Period between the last and the current pregnancy } & 1 year & 21 & $3.0 \%$ \\
\cline { 2 - 4 } & 2 years & 58 & 125 \\
\cline { 2 - 4 } & 3 years or more & 346 & $18.1 \%$ \\
\cline { 2 - 4 } & No previous pregnancy & 163 & $50.0 \%$ \\
\hline Are you planning for future pregnancy? & No & 407 & $23.6 \%$ \\
\cline { 2 - 4 } & Yes & 285 & $58.8 \%$ \\
\hline
\end{tabular}




\begin{tabular}{|l|l|l|l|}
\hline Are you suffering from any postpartum problems? & No & 624 & $90.2 \%$ \\
\cline { 2 - 5 } & Yes & 68 & $9.8 \%$ \\
\hline \multirow{2}{*}{ Do you use drugs? } & No & 587 & $85.1 \%$ \\
\cline { 2 - 5 } & Yes & 103 & $14.9 \%$ \\
\hline
\end{tabular}

Table 3: Breast feeding behavior

\begin{tabular}{|l|l|l|l|}
\hline \multicolumn{2}{|l|}{} & $\mathbf{N}$ & $\%$ \\
\hline \multirow{2}{*}{ Do you have previous breast-feeding experience? } & No & 135 & $19.5 \%$ \\
\cline { 2 - 4 } & Yes & 557 & $80.5 \%$ \\
\hline \multirow{2}{*}{$\begin{array}{l}\text { If you have ever breastfed, how long did you } \\
\text { exclusively breastfeed? }\end{array}$} & $<2$ Months & 73 & $13.2 \%$ \\
\cline { 2 - 4 } & $2-4$ Months & 90 & $16.3 \%$ \\
\cline { 2 - 4 } & $4-6$ Months & 118 & $21.3 \%$ \\
\cline { 2 - 4 } & $>6$ Months & 272 & $49.2 \%$ \\
\hline \multirow{2}{*}{ Do you have exclusive breast feeding? } & No & 414 & $59.8 \%$ \\
\cline { 2 - 4 } & Yes & 278 & $70.2 \%$ \\
\hline \multirow{2}{*}{ Have you continued EBF after returning to work } & No & 486 & $20.2 \%$ \\
\cline { 2 - 4 } & Yes & $29.8 \%$ \\
\hline
\end{tabular}

EBF: Exclusive breast feeding

Table 4: Barriers that prevent mothers from continuing exclusive breast feeding after returning to the work

\begin{tabular}{|l|l|l|}
\hline & $\mathbf{N}$ & $\mathbf{\%}$ \\
\hline Combined causes & 316 & $61.4 \%$ \\
\hline Insufficient breast milk secretion & 90 & $17.5 \%$ \\
\hline No or minimal support from workplace for EBF & 34 & $6.6 \%$ \\
\hline Take medicines that excreted in the breast milk & 13 & $2.5 \%$ \\
\hline Concern if the baby takes enough feeding & 13 & $2.5 \%$ \\
\hline Breastfeeding takes a long time from the working schedule/ mothers schedule & 13 & $2.5 \%$ \\
\hline Became pregnant before completing the breastfeeding duration. & 10 & $1.9 \%$ \\
\hline Breastfeeding stress/ Lack the confidence about the ability to breastfed & 9 & $1.7 \%$ \\
\hline Formula feeding makes a good effect on babies' weight in comparison to breastfeeding & 7 & $1.4 \%$ \\
\hline Presence of infant illness that prevents breastfeeding & 3 & $0.6 \%$ \\
\hline Presence of mother illness that prevents breastfeeding & 2 & $0.4 \%$ \\
\hline Nipples pain or sores & 2 & $0.4 \%$ \\
\hline Minimal Family support/ partner support & 2 & $0.4 \%$ \\
\hline Fear of distortion of breast shape after breastfeeding & 1 & $0.2 \%$ \\
\hline
\end{tabular}

Table 5: Continuation of EBF after returning to work

\begin{tabular}{|c|c|c|c|c|c|c|}
\hline & & \multicolumn{4}{|c|}{ Have you continued EBF after returning to work } & \multirow[b]{3}{*}{ P value } \\
\hline & & \multicolumn{2}{|c|}{$\begin{array}{l}\text { No } \\
\mathrm{N}=486(\mathbf{7 0 . 2 \%}) \\
\end{array}$} & \multicolumn{2}{|c|}{$\begin{array}{l}\text { Yes } \\
\mathrm{N}=206(29.8 \%)\end{array}$} & \\
\hline & & $\mathbf{N}$ & $\%$ & $\mathbf{N}$ & $\%$ & \\
\hline \multirow[t]{9}{*}{ Occupation } & Teacher & 281 & $57.8 \%$ & 91 & $44.2 \%$ & \multirow[t]{9}{*}{$0.004 *$} \\
\hline & Administrative jobs & 79 & $16.3 \%$ & 33 & $16.0 \%$ & \\
\hline & Others & 54 & $11.1 \%$ & 34 & $16.5 \%$ & \\
\hline & Business & 30 & $6.2 \%$ & 25 & $12.1 \%$ & \\
\hline & physician/dentist & 12 & $2.5 \%$ & 11 & $5.3 \%$ & \\
\hline & Other job in health care sector & 17 & $3.5 \%$ & 3 & $1.5 \%$ & \\
\hline & Nurse & 6 & $1.2 \%$ & 5 & $2.4 \%$ & \\
\hline & Pharmacist & 6 & $1.2 \%$ & 4 & $1.9 \%$ & \\
\hline & Engineer & 1 & $0.2 \%$ & 0 & $0.0 \%$ & \\
\hline \multirow[t]{2}{*}{ Employment status } & Full-time & 342 & $70.4 \%$ & 122 & $59.2 \%$ & \multirow[t]{2}{*}{$0.005^{*}$} \\
\hline & Part-time & 144 & $29.6 \%$ & 84 & $40.8 \%$ & \\
\hline \multirow[t]{4}{*}{ Work shift } & Morning & 375 & $77.2 \%$ & 129 & $62.6 \%$ & \multirow[t]{4}{*}{$0.001^{*}$} \\
\hline & Multishift & 74 & $15.2 \%$ & 49 & $23.8 \%$ & \\
\hline & Evening & 34 & $7.0 \%$ & 24 & $11.7 \%$ & \\
\hline & Night & 3 & $0.6 \%$ & 4 & $1.9 \%$ & \\
\hline \multirow{2}{*}{$\begin{array}{l}\text { Are you suffering from any } \\
\text { postpartum problems }\end{array}$} & No & 429 & $88.3 \%$ & 195 & $94.7 \%$ & \multirow[t]{2}{*}{$0.011^{*}$} \\
\hline & Yes & 57 & $11.7 \%$ & 11 & $5.3 \%$ & \\
\hline \multirow[t]{2}{*}{ Do you use drugs? } & No & 403 & $83.3 \%$ & 184 & $89.3 \%$ & \multirow[t]{2}{*}{$0.047^{*}$} \\
\hline & yes & 81 & $16.7 \%$ & 22 & $10.7 \%$ & \\
\hline
\end{tabular}

*significant at $p<0.05$

$\underline{\text { WWW.ijirms.in }}$ 
Table 6: Relation between the barriers that discontinue exclusive breast feeding after returning to work and working in the health care sector

\begin{tabular}{|l|l|l|l|l|}
\hline \multirow{2}{*}{ Barriers } & \multicolumn{2}{|l|}{ Yorkers in healthcare sector } \\
\cline { 2 - 5 } & No & \multicolumn{2}{l|}{ P value } \\
\cline { 2 - 5 } & $\mathbf{N}$ & $\%$ & $\mathbf{N}$ & $\%$ \\
\hline Combined causes & 285 & $60.6 \%$ & 31 & $68.9 \%$ \\
\hline Insufficient breast milk secretion & 90 & $19.1 \%$ & 0 & $0.0 \%$ \\
\hline No or minimal support from workplace for EBF & 27 & $5.7 \%$ & 7 & $15.6 \%$ \\
\hline Take medicines that excreted in the breast milk & 12 & $2.6 \%$ & 1 & $2.2 \%$ \\
\hline Concern if the baby takes enough feeding & 11 & $2.3 \%$ & 2 & $4.4 \%$ \\
\hline Breastfeeding takes a long time from the working schedule/ mothers schedule & 10 & $2.1 \%$ & 3 & $6.7 \%$ \\
\hline Became pregnant before completing the breastfeeding duration & 9 & $1.9 \%$ & 1 & $2.2 \%$ \\
\hline Breastfeeding stress/ Lack the confidence about the ability to breastfed & 9 & $1.9 \%$ & 0 & $0.0 \%$ \\
\hline $\begin{array}{l}\text { Formula feeding makes a good effect on babies' weight in comparison to } \\
\text { breastfeeding. }\end{array}$ & 7 & $1.5 \%$ & 0 & $0.0 \%$ \\
\hline Presence of infant illness that prevents breastfeeding & 3 & $0.6 \%$ & 0 & $0.0 \%$ \\
\hline Presence of mother illness that prevents breastfeeding & 2 & $0.4 \%$ & 0 & $0.0 \%$ \\
\hline Nipples pain or sores & 2 & $0.4 \%$ & 0 & $0.0 \%$ \\
\hline Minimal Family support/ partner support & 2 & $0.4 \%$ & 0 & $0.0 \%$ \\
\hline Fear of distortion of breast shape after breastfeeding & 1 & $0.2 \%$ & 0 & $0.0 \%$ \\
\hline
\end{tabular}

*significant at $p<0.05$

Table 7: Breast feeding friendly work policy

\begin{tabular}{|c|c|c|c|}
\hline & & $\mathrm{N}$ & $\%$ \\
\hline \multirow[t]{2}{*}{ Does your workplace have breast feeding or breast milk-pumping place? } & No & 598 & $86.4 \%$ \\
\hline & Yes & 94 & $13.6 \%$ \\
\hline \multirow[t]{2}{*}{ Do you breast feed your infant during the work time? } & No & 592 & $85.5 \%$ \\
\hline & Yes & 100 & $14.5 \%$ \\
\hline \multirow[t]{2}{*}{ In your workplace, are there breastfeeding hours during work time? } & No & 560 & $80.9 \%$ \\
\hline & Yes & 132 & $19.1 \%$ \\
\hline \multirow[t]{2}{*}{ Do you have a strict full-time schedule that did not make you freely use the nursing break? } & No & 325 & $47.0 \%$ \\
\hline & Yes & 367 & $53.0 \%$ \\
\hline
\end{tabular}

Table 8: Relation between discontinuation of exclusive breast feeding after returning to work and Breastfeeding friendly work policies

\begin{tabular}{|c|c|c|c|c|c|c|}
\hline & & \multicolumn{4}{|c|}{ Have you continued EBF after returning to work } & \multirow[b]{3}{*}{ P value } \\
\hline & & \multicolumn{2}{|c|}{ No } & \multicolumn{2}{|c|}{ Yes } & \\
\hline & & $\mathbf{N}$ & $\%$ & $\mathbf{N}$ & $\%$ & \\
\hline \multirow[t]{2}{*}{ Does your workplace have breast feeding place } & No & 446 & $91.8 \%$ & 152 & $73.8 \%$ & \multirow[t]{2}{*}{$<0.001 *$} \\
\hline & Yes & 40 & $8.2 \%$ & 54 & $26.2 \%$ & \\
\hline \multirow[t]{2}{*}{ Do you breast feed your infant during the work time } & No & 450 & $92.6 \%$ & 142 & $68.9 \%$ & \multirow[t]{2}{*}{$<0.001^{*}$} \\
\hline & Yes & 36 & $7.4 \%$ & 64 & $31.1 \%$ & \\
\hline \multirow[t]{2}{*}{ Are there breastfeeding hours in your work } & No & 418 & $86.0 \%$ & 142 & $68.9 \%$ & \multirow[t]{2}{*}{$<0.001 *$} \\
\hline & Yes & 68 & $14.0 \%$ & 64 & $31.1 \%$ & \\
\hline \multirow{2}{*}{$\begin{array}{l}\text { Do you have a strict full-time schedule that did not make } \\
\text { you freely use the nursing break? }\end{array}$} & No & 232 & $47.7 \%$ & 93 & $45.1 \%$ & \multirow[t]{2}{*}{0.532} \\
\hline & Yes & 254 & $52.3 \%$ & 113 & $54.9 \%$ & \\
\hline
\end{tabular}

*significant at $p<0.05$

\section{Discussion}

Many factors contribute to the observed low breastfeeding rates. Determination of the country specific barriers is necessary for adequate relevant interventions at legal, social, and employment conditions levels, as well as the health-care services ${ }^{[14]}$. Therefore, this study aimed to assess the prevalence of EBF among working mothers in the western region of Saudi Arabia and the contributing barriers against the continuation of EBF.

In the present study, the frequency of EBF was $40.2 \%$, which was much lowered to $29.8 \%$ after returning to the work. Inconsistent reports regarding the prevalence of EBF in Saudi Arabia ranging from $1.7 \%$ to $24.4 \%$ have been found ${ }^{[15]}$. A comparable research work recruited Saudi females residing in Riyadh and Dammam cities. The study reported that only $37 \%$ of $\underline{\text { www.ijirms.in }}$ them continued EBF until 6 months ${ }^{[16]}$. Another study including mothers of different nationalities residing Tabuk city revealed $31.4 \%$ prevalence of $\mathrm{EBF}^{[11]}$. Al-Katufi et al. $(2020)^{[12]}$ identified higher prevalence of EBF (79\%) and after returning to the work $(59.5 \%)$ among primary health care workers in Al-Ahsa region, Saudi Arabia. They attributed these high rates to the high educational level and awareness among their studied sample. Other countries in the middle east showed variable reports about EBF. Rates of $1 \%$ (17), $1.9 \%$ (18), $9.7 \%$ (19), $18.9 \%$ (20), $54 \%$ (21), $66.4 \%$ (22) have been reported in Jordan, United Arab Emirates, Egypt, Qatar, Turkey, and Iran, respectively.

Moreover, a recent study that investigated breast feeding practices in rural areas of Southern Nepal detected 53\% prevalence of $\mathrm{EBF}^{[23]}$. As well, a recent study of Hauck et al. (2020) ${ }^{[24]}$ stated 
variable rates in the united states (25\%), in Canada (26\%), and in Brazil (41\%).

Several factors influence EBF including the level of urbanization of the residence place, the specific local culture and feeding traditions, and the parents' socioeconomic status, level of education, and employment conditions ${ }^{[25]}$.

The current survey revealed many barriers to EBF. Among them, insufficient breast milk secretion and the lack or minimal support from the workplace for EBF were commonly stated by the mothers. Comparable barriers were identified by AlKatufi et al. (2020) in Al-Ahsa region. However, they reported early returning to the work within 6 months of giving birth as the most common barrier. Our findings are supported by Mills (2009) [26] who recommended supplying workplaces with the necessary support systems to encourage EBF and increase its rates. Furthermore, the insufficient breast milk secretion might be attributed to the low percentage of latching-on (breast suckling by infants) practice by Saudi mothers ${ }^{[27]}$. Another study that included 517 Saudi mothers reported insufficient breast milk (25.9\%), getting pregnant while breastfeeding $(19.7 \%)$, and being a working mother $(15.9 \%)$ as the most common reasons for stopping breastfeeding ${ }^{[28]}$. Further study among school teachers in Abha Female Educational District identified insufficient breast milk and work-related problems as the main reasons for stopping breastfeeding before two years ${ }^{[29]}$.

The discontinuation of EBF after returning to the work was significantly higher among teachers, followed by workers in the administrative jobs, which agrees with an earlier survey among 384 female teachers in Abha region, Saudi Arabia ${ }^{[29]}$. Women who are working full-time or in the morning shift failed to continue exclusive breast feeding. This is in line with Sulaiman et al. (2016) [30] who studied the impact of working status on breastfeeding practices in urban Malaysia ${ }^{[30]}$. They reported that the working status is considered a partial barrier to maintain breastfeeding after the women return to the work if there is availability of workplace support and facilities. Earlier study provided evidence that mothers make decisions related to breastfeeding based on their workplace situation, such as working hours ${ }^{[31]}$. Furthermore, part-time work has been reported to increase the initiation and duration of breast feeding ${ }^{[32]}$.

Insufficient breast milk secretion and the perception that formula feeding makes a good effect on babies' weight were the most common barriers reported by the workers in the health care sector. In contrast, a previous study reported work-related problems as the most common cause for stopping breast feeding among the health care workers ${ }^{[33]}$. Actually, about $5 \%$ of women had physiologic insufficient milk supply, however much higher percentages have false perceptions of insufficient milk for their baby. These false beliefs are the reasons of the increased use of formula feeding ${ }^{[34]}$.

The present study showed great deficiencies in the breastfeeding friendly work policies including the absence of breast feeding or breast milk-pumping place (86.4\%), breastfeeding hours during work time $(80.9 \%)$, besides the presence of a strict full-time schedule that did not allow free use of the nursing break. Moreover, there was a significant association between these deficient policies and the discontinuation of the EBF after returning to the work. It is evident that work places without facilities for breastfeeding can undermine EBF. Accordingly, Cohen and Mrtek (1994) showed that women employed by "breastfeeding friendly" business establishments were able to maintain a breastfeeding regimen for at least six months at rates comparable to non-working women ${ }^{[35]}$.
In fact, supporting breastfeeding mothers at the workplace through providing facilities for expressing and storing breast milk in the workplace is very helpful for the mothers. This approach resolves the financial and family responsibilities, ensure both the economic and health benefits of breastfeeding and employment while employers benefit from retaining women at the work. The application of this legislation showed a significant impact (2.3 percentage points higher) upon breastfeeding rates in the United States ${ }^{[24]}$.

\section{Conclusion}

The present study shows low prevalence of exclusive breast feeding among working mothers in the Western region of Saudi Arabia. The discontinuation of EBF after returning to the work was significantly higher among teachers, followed by workers in the administrative jobs. Multiple barriers to continuing breast feeding have been detected; however, insufficient breast milk secretion and the lack of breastfeeding friendly work policies were common reasons.

\section{Limitation and Recommendation}

The present study is limited by being a cross-sectional survey that shows the barriers that are significantly associated with termination of breastfeeding, but a definite causal relationship cannot be established. The collected information evaluated the situation only during the time the study was conducted, and it was difficult to analyze trends of the problem over time. Further, the study reflected the condition only in the Western region of Saudi Arabia. So, a comprehensive study that covers multiple regions is recommended. In the light of the findings of this study, it is important to apply breastfeeding-friendly work policies all over Saudi Arabia.

\section{Declarations}

\section{Ethics approval and consent to participate}

The study was approved by the research ethics committee of Taif University.

Availability of data and materials: The datasets used and/or analyzed during the current study are available from the corresponding author on reasonable request.

\section{Competing interests}

No competing interests.

\section{Funding}

None

\section{Acknowledgements}

The authors gratefully acknowledge the cooperation of all participants

\section{References}

[1] Text WHOJBtc. Health topics, breastfeeding. 2017. 2017(1). 
[2] Gila-Díaz A, Carrillo GH, López de Pablo ÁL, Arribas SM, Ramiro-Cortijo D. Association between Maternal Postpartum Depression, Stress, Optimism, and Breastfeeding Pattern in the First Six Months. International Journal of Environmental Research and Public Health,. 2020;17(19):7153.

[3] Dieterich CM, Felice JP, O'Sullivan E, Rasmussen KM. Breastfeeding and health outcomes for the mother-infant dyad. Pediatric clinics of North America. 2013;60(1):3148.

[4] Duijts L, Jaddoe VW, Hofman A, Moll HA. Prolonged and exclusive breastfeeding reduces the risk of infectious diseases in infancy. Pediatrics. 2010;126(1):e18-25.

[5] Gartner LM, Morton J, Lawrence RA, Naylor AJ, O'Hare $\mathrm{D}$, Schanler RJ, et al. Breastfeeding and the use of human milk. Pediatrics,. 2005;115(2):496-506.

[6] Dietz WH, Hunter AS. Legal preparedness for obesity prevention and control: the public health framework for action. J Law Med Ethics. 2009;37 Suppl 1:9-14.

[7] Cooklin AR, Donath SM, Amir LH. Maternal employment and breastfeeding: results from the longitudinal study of Australian children. Acta Paediatr. 2008;97(5):620-3.

[8] Gielen AC, Faden RR, O'Campo P, Brown CH, Paige DM. Maternal employment during the early postpartum period: effects on initiation and continuation of breastfeeding. Pediatrics. 1991;87(3):298-305.

[9] Shommo S, Al-Shubrumi H. Breastfeeding knowledge, attitude and practice among mothers in Hail district, northwestern Saudi Arabia. IOSR Journal of Nursing and Health Science. 2014;3: 49-56.

[10] Tobaiqy M, Thomas D, MacLure A, MacLure K. Smokers' and Non-Smokers' Attitudes towards Smoking Cessation in Saudi Arabia: A Systematic Review. Int J Environ Res Public Health. 2020;17(21).

[11] Alzaheb RA. Factors Influencing Exclusive Breastfeeding in Tabuk, Saudi Arabia. Clinical medicine insights Pediatrics. 2017;11:1179556517698136-.

[12] Al-Katufi BA, Al-Shikh MH, Al-Hamad RF, Al-Hajri A, Al-Hejji A. Barriers in continuing exclusive breastfeeding among working mothers in primary health care in the ministry of health in Al-Ahsa region, Saudi Arabia. Journal of family medicine and primary care. 2020;9(2):957-72.

[13] Alsulaimani NA. Exclusive breastfeeding among Saudi mothers: Exposing the substantial gap between knowledge and practice. Journal of family medicine and primary care. 2019;8(9):2803-9.

[14] Rollins NC, Bhandari N, Hajeebhoy N, Horton S, Lutter CK, Martines JC, et al. Why invest, and what it will take to improve breastfeeding practices? Lancet. 2016;387(10017):491-504.

[15] Al Juaid DA, Binns CW, Giglia RC. Breastfeeding in Saudi Arabia: a review. Int Breastfeed J. 2014;9(1):1.

[16] Raheel H, Tharkar S. Why mothers are not exclusively breast feeding their babies till 6 months of age? Knowledge and practices data from two large cities of the Kingdom of Saudi Arabia. Sudanese journal of paediatrics. 2018;18(1):28-38.

[17] Abuidhail J, Al-Modallal H, Yousif R, Almresi N. Exclusive breast feeding (EBF) in Jordan: prevalence, duration, practices, and barriers. Midwifery. 2014;30(3):331-7.
[18] Radwan H. Patterns and determinants of breastfeeding and complementary feeding practices of Emirati Mothers in the United Arab Emirates. BMC Public Health. 2013;13:171.

[19] Al Ghwass MM, Ahmed D. Prevalence and predictors of 6-month exclusive breastfeeding in a rural area in Egypt. Breastfeed Med. 2011;6(4):191-6.

[20] Al-Kohji S, Said HA, Selim NA. Breastfeeding practice and determinants among Arab mothers in Qatar. Saudi Med J. 2012;33(4):436-43.

[21] Alikaşifoğlu M, Erginoz E, Gur ET, Baltas Z, Beker B, Arvas A. Factors influencing the duration of exclusive breastfeeding in a group of Turkish women. J Hum Lact. 2001;17(3):220-6.

[22] Veghari G, Mansourian A, Abdollahi A. Breastfeeding status and some related factors in northern iran. Oman Med J. 2011;26(5):342-8.

[23] Acharya D, Singh JK, Kandel R, Park JH, Yoo SJ, Lee K. Maternal Factors and the Utilization of Maternal Care Services Associated with Infant Feeding Practices among Mothers in Rural Southern Nepal. Int J Environ Res Public Health. 2019;16(11).

[24] Hauck K, Miraldo M, Singh S. Integrating motherhood and employment: A 22-year analysis investigating impacts of US workplace breastfeeding policy. SSM population health. 2020;11:100580-.

[25] Bagci Bosi AT, Eriksen KG, Sobko T, Wijnhoven TM, Breda J. Breastfeeding practices and policies in WHO European Region Member States. Public Health Nutr. 2016;19(4):753-64.

[26] Mills SP. Workplace lactation programs: a critical element for breastfeeding mothers' success. Aaohn j. 2009;57(6):227-31.

[27] El-Khedr SM, Lamadah SM. Knowledge, attitude and practices of Saudi women regarding breastfeeding at Makkah al Mukkaramah. J Biol Agriculture Health Care, . 2014;4:56-65.

[28] Alshebly M, Sobaih B. Attitudes of Saudi mothers towards breastfeeding. Sudan J Paediatr. 2016;16(1):316.

[29] Al-Binali AM. Breastfeeding knowledge, attitude and practice among school teachers in Abha female educational district, southwestern Saudi Arabia. International breastfeeding journal. 2012;7(1):10-.

[30] Sulaiman Z, Liamputtong P, Amir LH. The enablers and barriers to continue breast milk feeding in women returning to work. J Adv Nurs. 2016;72(4):825-35.

[31] Roe B, Whittington LA, Fein SB, Teisl MF. Is there competition between breast-feeding and maternal employment? Demography. 1999;36(2):157-71.

[32] Mandal B, Roe BE, Fein SB. The differential effects of full-time and part-time work status on breastfeeding. Health Policy. 2010;97(1):79-86.

[33] AL-BINALI AM. Knowledge, attitude and practice of breast-feeding among female health care workers in tertiary care hospitals. The Medical Journal of Cairo University,. 2012;80(2):159-64.

[34] Singh B. Knowledge, attitude and practice of breastfeeding-A case study. European Journal of Scientific Research,. 2010;40(3):404-22.

[35] Cohen R, Mrtek MB. The impact of two corporate lactation programs on the incidence and duration of 
breast-feeding by employed mothers. Am J Health Promot. 1994;8(6):436-41.

Open Access This article is licensed under a Creative Commons Attribution 4.0 International License, which permits use, sharing, adaptation, distribution and reproduction in any medium or format, as long as you give appropriate credit to the original author(s) and the source, provide a link to the Creative Commons license, and indicate if changes were made. The images or other third party material in this article are included in the article's Creative Commons license, unless indicated otherwise in a credit line to the material. If material is not included in the article's Creative Commons license and your intended use is not permitted by statutory regulation or exceeds the permitted use, you will need to obtain permission directly from the copyright holder. To view a copy of this license, visit https://creativecommons.org/licenses/by/4.0/.

(C) The Author(s) 2021 